\title{
Antiparkinsonian and Antioxidant Effects of Hydroalcoholic Extract of Camellia sinensis, Asparagus racemosus, Mucuna pruriens and their Combination
}

\author{
Mahendra Ashok Giri ${ }^{1, *}$, Rasika Dnyandeo Bhalke ${ }^{2}$, K Vanitha Prakash ${ }^{3}$, Sanjay Bhaskar Kasture ${ }^{4}$ \\ 'Department of Pharmacology, Rajarshi Shahu College of Pharmacy, Buldhana, Maharashtra, INDIA. \\ ${ }^{2}$ Sanjivani College of Pharmaceutical Education and Research, Pune University, Kopargaon, Maharashtra, INDIA. \\ Shri Sai Jyoti College of Pharmacy, Vattinagula Pally, Gandhipeth, Hyderabad, Telangana, INDIA. \\ 4Pinnacle Biomedical Research Institute, Bhopal, Madhya Pradesh, INDIA.
}

\begin{abstract}
Objectives: Because of environmental risk factors Parkinson's disease rate doubled in last decades. In upcoming decades rate of Parkinson's disease is expected to be 12 million people in aging population. Present treatments are having huge side effects and requires more combinations. Hence objective of this study is to provide herbal combination for Parkinson's disease with reduced side and adverse effects. Methods: The antiparkinsonian activity of HECS, HEAR, HEMP and Mixture was evaluated by using haloperidol induced catalepsy, reserpine induced hypolocomotion, tacrine induced vacuous chewing movements and orofacial brusts. Antioxidant activity was assessed by using DPPH radical and $\mathrm{H}_{2} \mathrm{O}_{2}$ scavenging assay. The results were analyzed by repeated measure ANOVA followed by Dunnett's test. Results: Significant reduction $(P<0.05)$ in haloperidolinduced catalepsy was observed in the all groups at the doses of 30 and $100 \mathrm{mg} / \mathrm{kg}$ when given orally. Mixture $30 \mathrm{mg} / \mathrm{kg}$ showed extremely significant $(P<0.001)$ reduction in duration of catalepsy. Pretreatment with Mixture at $100 \mathrm{mg} / \mathrm{kg}$ was significantly $(P<0.05)$ reduces Reserpine induced hypolocomotion which is more significant as compared with other treatments. Similarly, HECS $30 \mathrm{mg} / \mathrm{kg}$ and mixture was more effective $(P<0.05)$ than remaining extracts in reducing tacrine induced Vacuous
\end{abstract}

chewing movements. In tacrine induced orofacial brust Mixture and HEAR $30 \mathrm{mg} / \mathrm{kg}$ shows extremely significant $(P<0.001)$ reduction of orofacial brusts. Similarly Mixture and HECS $100 \mathrm{mg} / \mathrm{kg}$ is more effective than other treatment in tacrine induced tongue protrusion. In DPPH scavenging assay, all the extracts exhibited free radical scavenging activity. In DPPH assay the $\mathrm{IC}_{50}$ value of ascorbic acid, HECS, HEAR, HEMP and Mixture (1:1:1) was $14.99,18.44,26.51,23.19$ and $20.47 \mu \mathrm{g} / \mathrm{ml}$ respectively. Conclusion: 1:1:1 mixture show extremely significant antioxidant and anti-parkinsonian activity as compare with individual hydroalcoholic extract. Thus the studied combination possess potent antiparkinsonian effect.

Key words: Antioxidant, Antiparkinsons, Camellia sinensi, Asparagus racemosus, Mucuna prurines, Haloperidol, Reserpine, Tacrine.

\section{Correspondence}

Prof. Mahendra Ashok Giri

Rajarshi Shahu College of Pharmacy, Buldhana-443001, Maharashtra, INDIA.

Phone no: +91-9764489091

Email: mahi_jaan83@yahoo.com

DOI: 10.5330/ijpi.2020.4.99

\section{INTRODUCTION}

Parkinson's Disease (PD) is a complex multi-framework, neurodegenerative sickness. In spite of the fact that dominatingly saw as motor ailment, it likewise has incapacitating non-motor highlights, which are as often as possible missed and not treated. The degeneration of dopaminergic neurons is viewed as the underlying driver of the trademark traditional engine side effects and non-motor indications. Significant treatment objectives are to increase striatal dopamine levels with antecedent replacement and additionally decrease its breakdown. As the ailment advances, a consistent increment in the portion of levodopa is inescapable. Be that as it may, higher dosages cause engine intricacies of dyskinesia and dystonia and bargain clinical treatment. Based on the studies, it is known that mitochondrial dysfunction, Neuronal death in substantial nigra and changed oxidative stress are the two crucial cellular stress parameters playing important role in PD pathogenesis. In parkinsons disease tremors, bradykinesia, stiffness in limbs and torso and postural instability are the four main symptoms. The focal point of the executives is the alleviation of the clinically prevailing motor side effects of PD. In any case, presently, there is an expanding acknowledgment of the non-motor highlights of $\mathrm{PD}$, which additionally need consideration. These highlights are rest aggravations, constipation, psychological decay, melancholy, dread, tension, bladder issues, weight changes, weakness and loss of vitality, autonomic brokenness/hypotension and sexual issues. These can be predominant and incapacitating in a sizeable number of patients, influencing a mindblowing nature. PD additionally has pre-malady manifestations like blockage and loss of smell, decreased outward appearances, soft tone, rest changes, wooziness which go before months to decades before clinical determination of PD. The current restorative technique against PD essentially depends on reestablishing the ideal degree of dopamine (DA) and its related flagging pathways, for which Levodopa or L-DOPA (L3, 4-dihydroxyphenylalanine), a forerunner of dopamine is regulated to the PD patients. L-DOPA gives introductory advantage by hindering the malady movement; be that as it may, long haul benefits are impossible. Additionally, it is likewise directed in blend with carbidopa, a fringe decarboxylase inhibitor. This aides in reducing the reaction of L-DOPA which principally incorporate gastrointestinal and cardiovascular issues. Another procedure for PD treatment is the utilization of monoamine oxidase $\mathrm{B}$ (MAO-B) inhibitors. The movement of MAO-B compound is expanded by virtue of DA metabolism which hoists oxidative stress and mitochondrial dysfunctions. Until this point, mitochondrial brokenness and adjusted oxidative stress are viewed as the conceivable system prompting neuronal cell death. Therefore, therapeutic approaches 
that optimize ROS and enhance mitochondrial function are being thoroughly considered in the current scenario. There is a generous extension to benefit of the modalities of conventional information in the administration for both the non-motor and pre-disease highlights of PD. Exploration during the most recent multi decade has distinguished a few plants that show restorative property against neurodegenerative issues like $\mathrm{PD}$ and $\mathrm{AD}{ }^{1,2}$ Therefore, the present study aims to investigate antioxidant and neuroprotective activity of Mucuna pruriens, Camellia sinensis and Asparagus racemosus in combination to get rid from side effects of L-DOPA and also development of novel therapeutic approach against PD to address each cardinal sign of PD by using these herb with different potential.

Mucuna pruriens L. (Family: Fabaceae) is a tropical legume plant usually known as velvet beans. Mucuna pruriens is generally exploited for the treatment of Parkinsonism and dissimilar sorts of sexual debilities. It also acts as an aphrodisiac, anti-snake venom, antidiabetic, antioxidant and have a strong potential to improve the fertility of sperm. It has immense medicinal properties specifically due to high L-DOPA (L-3,4dihydroxyphenylalanine) content and its role in parkinsons disease. Besides L-DOPA it also contains glycoside, gallic acid, glutathione, Levodopa. It improves locomotor and behaviour function, alleviate oxidative stress, metal chelation, mitochondrial and synaptic function. ${ }^{3,4}$ Camellia sinensis is popularly known as Green Tea belonging to Theaceae family. Green tea and its bioactive constituents are most popular for their cell reinforcement properties, prompting clinical examinations in ailments related with responsive oxygen species, for example, malignancy or cardiovascular and neurodegenerative maladies. The most important phytoconstituents of Camellia sinensis are polyphenolic compounds known as catechins including Epigallocatechin Gallate (EGCG), Catechin (C), Epicatechin (EC), Gallocatechin (GC), Gallocatechin Gallate (GCG), Epigallocatechin (EGC) and Epicatechin Gallate (ECG). Flavonols add values to the oxidative damage prevention capacities of tea leaves. The aglycones of the fundamental flavonols in tea leaves are quercetin, kaempferol and myricetin. Polyphenols, for example, epigallocatechin gallate, because of their mitigating and antioxidant impacts, are known to introduce neuroprotective properties, what could clarify their advantages in neurodegenerative illnesses. ${ }^{5-7}$

Asparagus racemosus, otherwise called shatavari (family Asparagaceae), is a significant therapeutic plant endemic to tropical India and Thailand. It is notable medication in Ayurvedic rasayana that forestall maturing, increment life span and improve mental capacity. Also, it is suggested in Ayurvedic messages for the avoidance and treatment of gastric ulcers, dyspepsia and as a galactagogue. The significant dynamic mixes in the root are steroidal saponins, for example, asparacoside, shatavarin IV, V and XI and different constituents, for example, racemosol and asparagamine. It indicated high free radical searching just as neurotropic modulatory properties in infections related with neuron cell misfortune. The anti-PD compounds present in A. racemosus include racemosol and rhamnose. ${ }^{8,9}$

The neuroprotective effects of Mucuna pruriens, Camelia sinensis and Asperagus racemosus extract in PD animal model have been reported by many researchers. However, the neuroprotective effect of combination is not reported hence present study aims at studying antiparkinsonian and antioxidant activity of these herbs in order to minimized side effects of available therapies and addressed motor and non-motor symptoms.

\section{MATERIALS AND METHODS}

\section{Experimental Animals}

Experiments were performed utilizing male Wistar rodents (Rats) weighing $180-200 \mathrm{~g}$. Creatures were kept up at $22^{\circ} \mathrm{C} \pm 2^{\circ} \mathrm{C}$ on a standard pellet diet and tap water ad libitum. Institutional Animal Ethics Committee for Animal Experiments of Sanjivani College of Pharmaceutical Education and Research, Kopargaon approved the study under the protocol SCPER/CPCSEA/IAEC/2019-20/01 and all experiments were conducted in accordance with guidelines of Committee for the Purpose of Control and Supervision of Experiments on Animals (CPCSEA). Behavioral tests were performed during the light cycle between 10.00 a.m. and 4.00 p.m.

\section{Drugs and Chemicals}

Tacrine and Reserpine were purchased from Sigma, Aldrich, Mumbai. All other chemicals used were of analytical grade and purchased from standard manufacturer.

\section{Plant material and extraction}

Dry powder of Mucuna pruriens seeds, Asperagus racemosus roots and Camelia sinensis leaves was purchased from local market and were authenticated from Department of Pharmacognosy, Sanjivani College of Pharmaceutical Education and Research, Kopargaon.

Hydroalcoholic extracts were prepared using Soxhlet's extractor. The extracts were filtered and dried. Extracts were subjected to phytochemical screening. ${ }^{10}$ The extracts were administered in doses of 30 and $100 \mathrm{mg} / \mathrm{kg}$ (p.o.). Control group was given only vehicle in equivalent volume of plant extract.

\section{Experimental design}

Animals were randomly divided into following groups of 5 animals each. Group I - Control

Group II - Haloperidol $(0.5 \mathrm{mg} / \mathrm{kg})$ or Reserpine $(1 \mathrm{mg} / \mathrm{kg})$ or Tacrine (5 mg/kg),

Group III - HEMP (30 mg/kg),

Group IV - HEMP (100 mg/kg), Group V - HECS (30 mg/kg),

Group VI - HECS (100 mg/kg),

Group VII - HEAR (30 mg/kg),

Group VIII - HEAR (100 mg/kg),

Group IX - 1:1:1 Mixture (30 mg/kg),

Group X - 1:1:1 Mixture (100 mg/kg).

These groups were used for treatment of Parkinson's symptoms.

\section{Assessment of anti-parkinsonian activity Haloperidol induced catalepsy}

Male Wistar rats (weighing 180-200 g) were divided into ten groups of five each. Rats were pretreated with vehicle, HECS (30 and $100 \mathrm{mg}$ / $\mathrm{kg}$, p.o.), HEAR (30 and $100 \mathrm{mg} / \mathrm{kg}$, p.o.), HEMP (30 and $100 \mathrm{mg} / \mathrm{kg}$, p.o.), 1:1:1 HECS:HEAR:HEMP (30 and $100 \mathrm{mg} / \mathrm{kg}$, p.o.) $30 \mathrm{~min}$ before haloperidol $(0.5 \mathrm{mg} / \mathrm{kg}$, intra-peritoneally). Post administration of haloperidol duration of catalepsy was measured at $0,30,60,90,120,150$ and 180 min utilizing bar test. Both the forepaws of the animals were placed on a wooden bar raised above the ground. The cutoff time (time for which animal was placed on elevated bar) was $300 \mathrm{sec}^{11,12}$

\section{Tacrine induced jaw movements}

The observation chamber consisted of a clear Plexiglas box measuring $28 \times 28 \times 28 \mathrm{~cm}^{3}$, which had a wire mesh floor. The box was elevated 42 $\mathrm{cm}$ from the surface of the table, allowing behavioral observation from all angles. Rats were divided into groups and treated with vehicle, HECS (30 and $100 \mathrm{mg} / \mathrm{kg}$, p.o.), HEAR (30 and $100 \mathrm{mg} / \mathrm{kg}$, p.o.), HEMP (30 and $100 \mathrm{mg} / \mathrm{kg}$, p.o.) and 1:1:1 HECS:HEAR:HEMP (30 and $100 \mathrm{mg} /$ $\mathrm{kg}$, p.o.). After $20 \mathrm{~min}$, tacrine (5 $\mathrm{mg} / \mathrm{kg}$ i.p.) was administered and the 
number of chewing movements, orofacial bursts and tongue protrusions were measured every ten $\min$ for 60 min. ${ }^{13,14}$

\section{Reserpine-induced hypolocomotion}

Reserpine was injected intraperitoneally at a dose of $1 \mathrm{mg} / \mathrm{kg}$ in a suspension with Tween-80, $1 \mathrm{~h}$ after the mice were treated with vehicle, HECS (30 and $100 \mathrm{mg} / \mathrm{kg}$, p.o.), HEAR (30 and $100 \mathrm{mg} / \mathrm{kg}$, p.o.), HEMP (30 and $100 \mathrm{mg} / \mathrm{kg}$, p.o.) and 1:1:1 HECS:HEAR:HEMP (30 and 100 $\mathrm{mg} / \mathrm{kg}$, p.o.). The effect of the study compounds on reserpine-induced hypolocomotion was assessed using Actophotometer (Dolphine, India). The locomotor activity of the animals was measured for $2 \mathrm{~min}$, at $2 \mathrm{~h}, 3 \mathrm{~h}$ and $4 \mathrm{~h}$ after reserpine had been administered. ${ }^{15}$

\section{Antioxidant activity \\ DPPH scavenging assay}

The free radical scavenging activity of the HEMP, HECS and HEAR was measured in terms of hydrogen donating or radical scavenging ability using the stable free radical DPPH. $0.1 \mathrm{mM}$ solution of DPPH in methanol was prepared and $1 \mathrm{ml}$ of this solution was added to $3 \mathrm{ml}$ of HEMP, HECS and HEAR solution in water at various concentrations (2$1000 \mu \mathrm{g} / \mathrm{ml}$ ). The mixture was incubated for $45 \mathrm{~min}$ at room temperature and the absorbance was measured at $517 \mathrm{~nm}$ against the corresponding blank solution. Ascorbic acid was used as reference standard. Percentage inhibition of DPPH free radical was calculated using the following equation:

\section{DPPH Scavenged $(\%)=[(\mathrm{Ac}-\mathrm{At}) / \mathrm{Ac}] \times 100$}

Where $A c$ : absorbance of the control and At: absorbance of the extract or reference standard. The antioxidant activity was expressed as $\mathrm{IC}_{50}$. The $\mathrm{IC}_{50}$ value was defined as the concentration in $\mu \mathrm{g} / \mathrm{ml}$ of the extract that inhibits the formation of DPPH radicals by $50 \% .{ }^{16-18}$

\section{Statistical analysis}

Results were expressed as mean \pm SEM. Significant differences between groups were determined by analysis of variance test followed by Dunnett's test.

\section{RESULTS}

\section{Haloperidol Induced catalepsy}

In haloperidol induced cataleptic animal model mixture $30 \mathrm{mg} / \mathrm{kg}$ shows extremely significant reduction in cataleptic phase as shown in Figure 1 . Followed by mixture $30 \mathrm{mg} / \mathrm{kg}, 100 \mathrm{mg} / \mathrm{kg}$ also shows extremely significant reduction in catalepsy. Almost all the hydroalcoholic extracts shows significant reduction in catalepsy induced by haloperidol but when combined in 1:1:1 proportion mixture shows extremely significant reduction with reduced dose of individual extract of Camelia sinensis, Asparagus racemosus and Mucuna pruriens as revealed in Figure 1.

\section{Reserpine Induced Hypolocomotion}

Hydro alcoholic extract of Camelia sinensis, Asparagus racemosus and Mucuna pruriens are studied for locomotors activity and hypolocomotion was induced with reserpine. In reserpine induced hypolocomotion hydro alcoholic extract shows significant increase in locomotors activity but as compare with low dose of $30 \mathrm{mg} / \mathrm{kg}, 100$ $\mathrm{mg} / \mathrm{kg}$ of HECS, HEAR and mixture shows more significant increase in locomotors activity. Mixture of $100 \mathrm{mg} / \mathrm{kg}$ shows extremely significant increase in locomotion and mixture $30 \mathrm{mg} / \mathrm{kg}$ shows very significant effect at first and third hour as exposed in Figure 2.

\section{Tacrine Induced Vacuous Chewing Movement (VCM)}

In tacrine induced vacuous chewing movements hydroalcoholic extract of Camelia sinensis at dose of $100 \mathrm{mg} / \mathrm{kg}$ shows extremely significant reduction in vacuous chewing movements followed by $30 \mathrm{mg} / \mathrm{kg}$. Mixture of $30 \mathrm{mg} / \mathrm{kg}$ and $100 \mathrm{mg} / \mathrm{kg}$ subsequently shows very significant reduction in tacrine induced vacuous chewing movements followed by significant reduction observed in HEAR and HEMP at 30 and $100 \mathrm{mg} /$ $\mathrm{kg}$ dose as presented in Figure 3.

\section{Tacrine Induced Orofacial Brust (OB)}

In tacrine induced orofacial brust mixture at $30 \mathrm{mg} / \mathrm{kg}$ shows extremely significant reduction as compare to $100 \mathrm{mg} / \mathrm{kg}$. Apart from that HECS $100 \mathrm{mg} / \mathrm{kg}$ and HEAR $30 \mathrm{mg} / \mathrm{kg}$ individually shows extremely significant reduction in orofacial brust. HECS $30 \mathrm{mg} / \mathrm{kg}$, HEAR $100 \mathrm{mg} /$ $\mathrm{kg}$, HEMP $30 \mathrm{mg} / \mathrm{kg}$ and HEMP $100 \mathrm{mg} / \mathrm{kg}$ shows significant reduction in tacrine induced orofacial brust individually as shown in Figure 4.

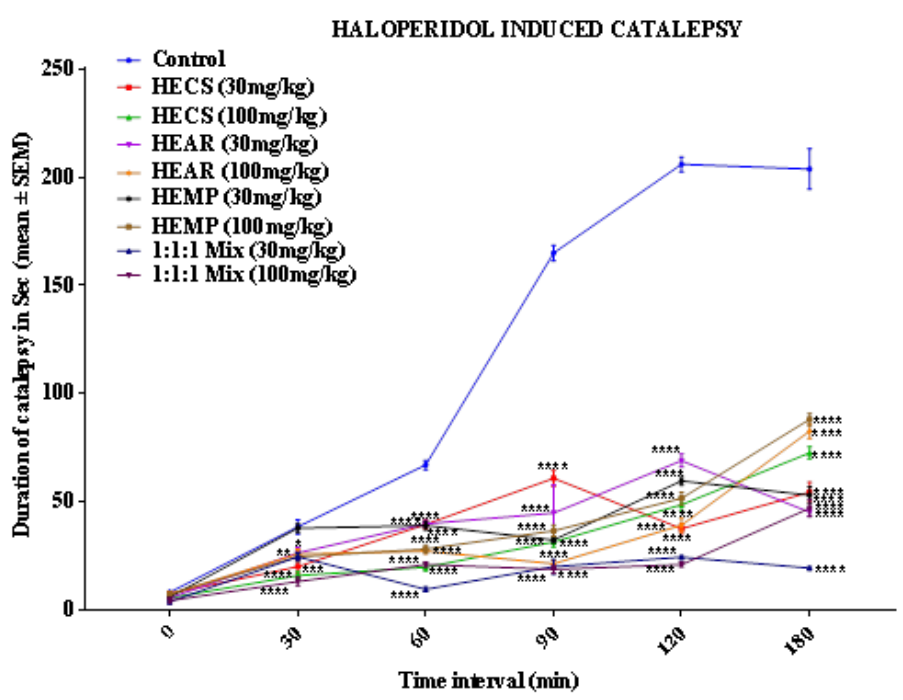

Figure 1: Effect of HECS, HEAR, HEMP and its combination on Haloperidol induced catalepsy. All the values are expressed as mean $\pm \mathrm{SEM} ; \mathrm{n}=5,{ }^{*} p<0.05$, ${ }^{* *} p<0.01,{ }^{* * *} p<0.001,{ }^{* * * *} p<0.0001$ significant compared to control (repeated measures ANOVA followed by Dunnett's test).

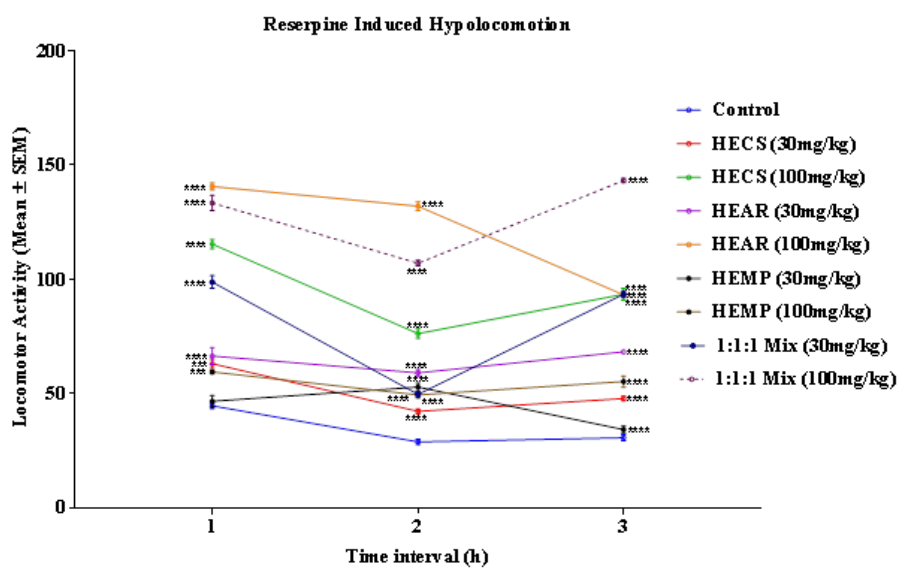

Figure 2: Effect of HECS, HEAR, HEMP and its combination on Reserpine induced Hypolocomotion. All the values are expressed as mean $\pm S E M ; n=5$, ${ }^{*} p<0.05,{ }^{* *} p<0.01,{ }^{* * *} p<0.001,{ }^{* * * *} p<0.0001$ significant compared to control (repeated measures ANOVA followed by Dunnett's test). 


\section{Tacrine Induced Tongue Protrusion (TP)}

In tacrine induced tongue protrusion Mixture $30 \mathrm{mg} / \mathrm{kg}$ and $100 \mathrm{mg} / \mathrm{kg}$ shows extremely significant reduction in tongue protrusion along with individual treatment of HECS $30 \mathrm{mg} / \mathrm{kg}$. HECS $100 \mathrm{mg} / \mathrm{kg}$, HEAR 30 and $100 \mathrm{mg} / \mathrm{kg}$, HEMP 30 and $100 \mathrm{mg} / \mathrm{kg}$ shows significantly reduction in tongue protrusion as displayed in Figure 5.

\section{DPPH scavenging assay}

HECS shown strong DPPH scavenging activity followed by 1:1:1 mixture. The scavenging effect of HECS, HEAR, HEMP and mixture was comparable to ascorbic acid. The $\mathrm{IC}_{50}$ value of Ascorbic acid, HECS, HEAR, HEMP and mixture was 14.99, 18.44, 26.51, 23.19 and 20.47 $\mu \mathrm{g} / \mathrm{ml}$ respectively. As compared with ascorbic acid HECS and mixture shows strong antioxidant effect as revealed in Figure 6.

\section{DISCUSSION}

Blocked dopamine D2 receptor shows extrapyramidal side effect as catalepsy, ${ }^{19}$ haloperidol blocks D2 receptor and causes development of

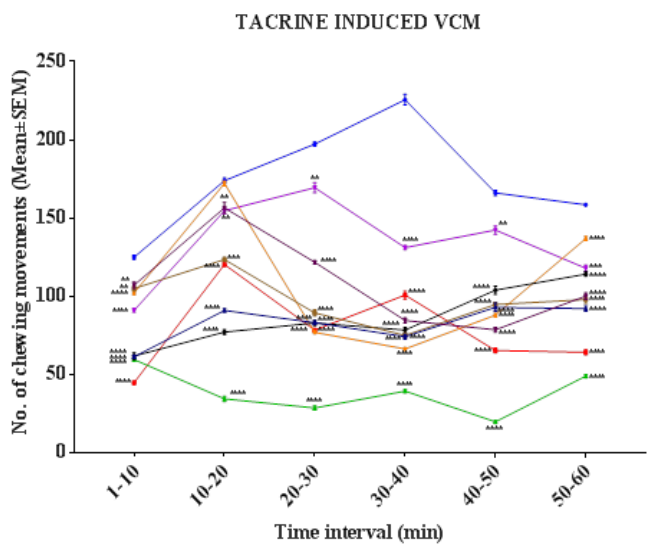

- Control

$\rightarrow \operatorname{HECS}(30 \mathrm{mg} / \mathrm{kg})$

$\rightarrow$ HECS $(100 \mathrm{mg} / \mathrm{kg})$

- HEAR $(30 \mathrm{mg} / \mathrm{kg})$

- HEAR $(100 \mathrm{mg} / \mathrm{kg})$

$\rightarrow$ HEMP $(30 \mathrm{mg} / \mathrm{kg})$

$\rightarrow$ HEMP $(100 \mathrm{mg} / \mathrm{kg})$

- 1:1:1 Mix $(30 \mathrm{mg} / \mathrm{kg})$

- 1:1:1 Mix $(100 \mathrm{mg} / \mathrm{kg})$

Figure 3: Effect of HECS, HEAR, HEMP and its combination on Tacrine induced VCM. All the values are expressed as mean \pm SEM; $n=5,{ }^{*} p<0.05,{ }^{* *} p<0.01$, ${ }^{* * *} p<0.001,{ }^{* * * *} p<0.0001$ significant compared to control (repeated measures ANOVA followed by Dunnett's test).

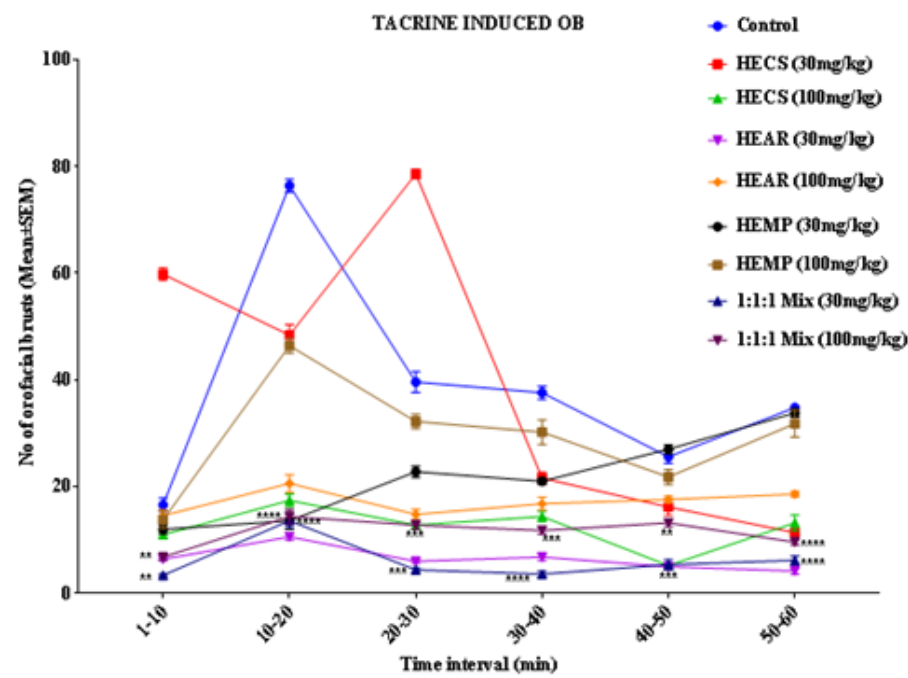

Figure 4: Effect of HECS, HEAR, HEMP and its combination on Tacrine induced $\mathrm{OB}$. All the values are expressed as mean $\pm \mathrm{SEM} ; n=5,{ }^{*} p<0.05,{ }^{* *} p<0.01$, ${ }^{* * *} p<0.001,{ }^{* * * *} p<0.0001$ significant compared to control (repeated measures ANOVA followed by Dunnett's test). catalepsy in mice. Nishchal et al. (2014) states that antipsychotic drugs such as haloperidol used to treat schizophrenia causes loss of correction in externally imposed posture and development of behavioral state called catalepsy. ${ }^{20}$ Camelia sinensis has epigallocatechine gallate like polyphenols which are an active ingredient shows curation in protective properties of brain against specific diseases and improvement in brain functioning like mental health and boosted mood. ${ }^{21}$ Various active polyphenols present in Camelia sinensis plays important role in reduction in catalepsy. Nabavi et al. (2017) proved that catechins present in Camelia sinensis reduces depression by means of inhibiting monoamine oxidase (MAO).$^{22}$ Elsaid et al. (2015) stated that accumulation of reactive oxygen species produces oxidative stress in brain causes neurotoxicity and antioxidant property of Aspargus officinalis have potentials to protect neuronal damage caused by reactive oxygen species. ${ }^{23}$ As

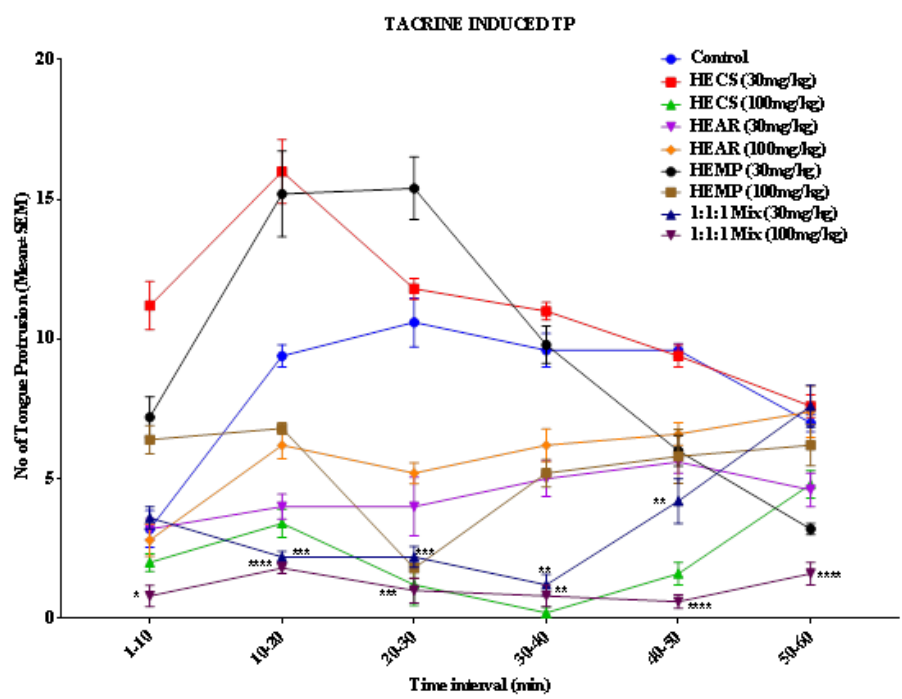

Figure 5: Effect of HECS, HEAR, HEMP and its combination on Tacrine induced TP. All the values are expressed as mean \pm SEM; $n=5,{ }^{*} p<0.05,{ }^{* *} p<0.01$, ${ }^{* * *} p<0.001,{ }^{* * * *} p<0.0001$ significant compared to control (repeated measures ANOVA followed by Dunnett's test).

\section{ANTIOXIDANT ACTIVITY BY DPPH METHOD}

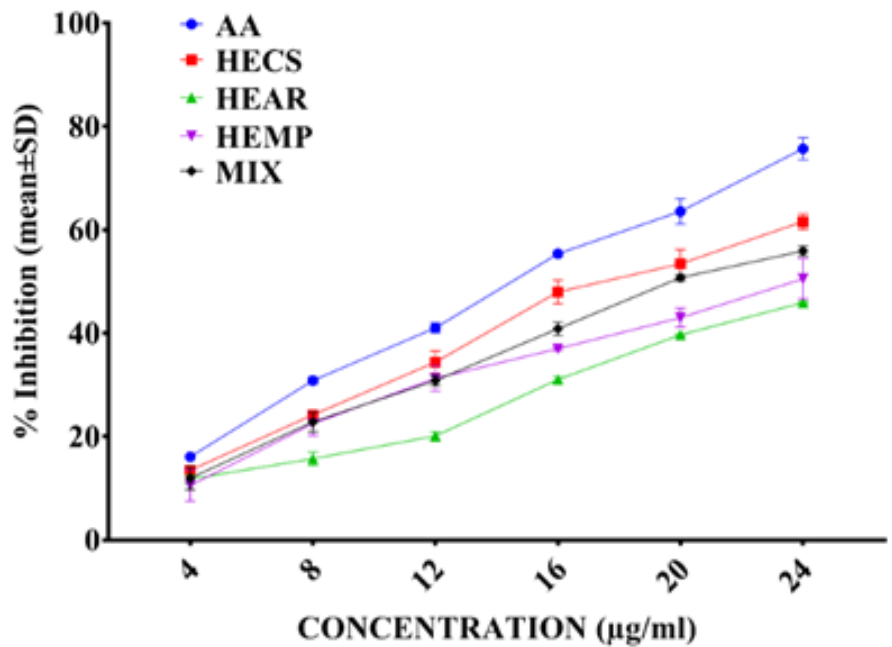

Figure 6: Percent inhibition shown by Ascorbic acid, HECS, HEAR, HEMP and 1:1:1 Mixture in DPPH scavenging assay. All the values are expressed in mean $\pm \mathrm{SD}$. 
Giri, et al:: Antioxidant and Antiparkinsonian effect of Camellia sinensis, Asparagus racemosus and Mucuna pruriens

per the study of Periera et al. (2020) reduction in straiatal dopamine levels and short-term memory impairments are seen after Reserpine administration in rats which mimics the pre-motor phase of Parkinson's disease. ${ }^{24}$ Dopamine depletion causes hypersensitivity of D2 receptors in corticostriatal terminals hence dopamine metabolism results in reduced dopamine release in synaptic cleft shows early and late impairment in behavior and social recognition tasks (Periera et al. 2020). ${ }^{24}$ Dopamine and 5 hydroxy tryptamine are responsible for regulation of mood in brain, however our study reveals that improved in locomotion activity with Camelia sinensis was might be due to its effect on increased levels of 5 hydroxy tryptamine in brain region. ${ }^{25}$ In present study we observe that the extract of Camelia sinensis significantly shows improvements in haloperidol induced catalepsy, reserpine induced hypolocomotion and tacrine induced vacuous chewing movements and are due to the direct or indirect effect of chemical constituents present in extract. Estrogen plays vital role in various parts of brain via estrogen receptors. One of the major function associated with estrogen via estrogen receptor in hippocampus and cerebral cortex region is modulating the function of brain-derived neurotrophic factor levels and improving learning and memory impairments. ${ }^{8}$ Lalert et al. (2013) have reveled in previous study that root extract of Asparagus racemosus reverses learning and memory impairments in overiectomized rats. ${ }^{26}$ The effect of the root extract was due to direct effect on the estrogen receptor without enhancing the estrogen levels. ${ }^{8}$ Various chemical components present in Asparagus racemosus root extract such as steroidal saponins (like asparacosides, shatavarin iv, $\mathrm{v}$ and $\mathrm{xi}$ ), racemosal and asparagamine are might be shows significant neuroprotection. Present study result revels that the root extract of Asparagus racemosus shows significant improvements in catalepsy, hypolocomotion and vacuous chewing movements are also due to the presence of different chemical constituents. Reserpine by showing effect on vesicular monoamine transporter 2 proteins reduces storage for biogenic amines and causes monoamine oxidase to actively deplete biogenic amines such as serotonin, dopamine and norepinephrines (Hedgecok et al. 2019). ${ }^{27}$ Lebowitz and Khoshbouei (2020) stated that dopamine signaling simplified as neurobiological substrate for salient stimuli and as per the stimuli goal oriented movement. ${ }^{28}$ As dopamine plays an important role in movement, resepine induced depletion of dopamine causes movement related disorgniztion such as hypolocomotion. Mucuna pruriens contains main and active chemical constituent as L-dopa which has a dose dependant toxic effect with other chemical constituents present in Mucuna pruriens such as hallucinogenic tryptamines and anti-nutritional factors phenols and tannins. ${ }^{29,30}$ Extract of Mucuna pruriens seed due to presence of chemical constituent such as L-dopa possess anti-parkinsonian effect at various animal models used for development of parkinsonian symptoms. Tacrine causes increase in acetylcholine levels at cholinergic synapses by blocking enzyme called acetylcholinestarase which is responsible for hydrolysis of acetylcholine. Cousins et al. (1997) reported that enhanced concentration of acetylcholine by anticholinestarase tacrine produces parkinsonian side effects such as bradikinesia, rigidity, treamor and in rats it shows purposeless chewing movement. ${ }^{31}$ Hence for study we are using tacrine induced vacuous chewing movement animal model for motor effects. DPPH assay is reliable parameter for mesurement of antioxidant activity. All the extracts shown antioxidant potentials due to various chemical constituents present in extract as compared with ascorbic acid but HECS and 1:1:1 mixture shows extremly significant antioxidant potentials as compare with other treatnet groups.

\section{CONCLUSION}

Present study revels that hydroalcoholic extracts of Camelia sinensis, Asparagus racemosus and Mucuna pruriens possess significant effect on haloperidol induced catalepsy, reserpine induced hypolocomotion and tacrine induced vacuous cheawing movements individually but when combination was used for the same study shows extreamly significant effects in dose related manner because of number of additional chemical constituents and their lower concentrations present in the mixture.

\section{ACKNOWLEDGEMENT}

The authors are thankful to the Institute of Sanjivani College of Pharmaceutical Education and Research, Kopargaon, for providing the necessary facilities for carry out our research work in the current format.

\section{CONFLICT OF INTEREST}

The authors declare that they have no competing interests.

\section{ABBREVIATIONS}

AA: Ascorbic acid; Ac: Absorbance of control; At: Absorbance of extract; DPPH: 2,2 -diphenyl - 1 - picrylhydrazyl; HEAR: Hydroalcoholic extract of Asparagus racemosus; HECS: Hydroalcoholic extract of Camellia cinensis; HEMP: Hydroalcoholic extract of Mucuna pruriens; MIX: Mixture; OB: Orofacial brust; VCM: Vacuous chewing movement.

\section{REFERENCES}

1. Srivastav S, Fatima M, Mondal AC. Important medicinal herbs in Parkinson's disease pharmacotherapy. Biomed Pharmacother. 2017;92:856-63.

2. Pathak-Gandhi N, Vaidya ADB. Management of Parkinson's disease in Ayurveda: Medicinal plants and adjuvant measures. J Ethnopharmacol. 2017;197:46-51.

3. Singh SK, Dhawan SS, Lal RK, Shanker K, Singh M. Biochemical characterization and spatio-temporal analysis of the putative I-DOPA pathway in Mucuna pruriens. Planta. 2018;248(5):1277-87.

4. Guest J, Grant R. The Benefits of Natural Products for Neurodegenerative Diseases. Adv Neurobiol. 2016;12:199-228.

5. Bedrood Z, Rameshrad M, Hosseinzadeh H. Toxicological effects of Camellia sinensis (green tea): A review. Phytotherapy Research. John Wiley and Sons Ltd. 2018;(7):1163-80.

6. Williams RJ, Spencer JPE. Flavonoids, cognition and dementia: Actions, mechanisms and potential therapeutic utility for Alzheimer disease. Free Radical Biology and Medicine. 2012;(1):35-45.

7. Bitu PN, DaSilva AB, Neves KRT, SilvaAH, Leal LKAM, Viana GSB. Neuroprotective Properties of the Standardized Extract from Camellia sinensis (Green Tea) and Its Main Bioactive Components, Epicatechin and Epigallocatechin Gallate, in the 6-OHDA Model of Parkinson's Disease. Evidence-based Complement Altern Med. 2015.

8. Lalert L, Kruevaisayawan $H$, Amatyakul $P$, Ingkaninan $K$, Khongsombat O. Neuroprotective effect of Asparagus racemosus root extract via the enhancement of brain-derived neurotrophic factor and estrogen receptor in ovariectomized rats. J Ethnopharmacol. 2018;225:336-41.

9. Banjari I, Marček T, Tomić S, Waisundara VY. Forestalling the Epidemics of Parkinson's Disease Through Plant-Based Remedies. Front Nutr. 2018;5:1-9.

10. Trease and Evans. Elsevier: Trease and Evans' Pharmacognosy, $16^{\text {th }}$ Edition: Evans. 2009;121-35. Available from: https://www.elsevier.ca/ca/product. jsp?isbn=9780702029332.

11. Nair SV, Arjuman A, Dorababu P, Gopalakrishna HN, Rao UC, Mohan L. Effect of NR-ANX-C (a polyherbal formulation) on haloperidol induced catalepsy in albino mice. Indian J Med Res. 2007;126(5):480-4.

12. Somani RS, Kasture VS, Kasture SB. Haloperidol inhibits (-) bicuculline-induced seizures and bicuculline potentiates haloperidol-induced catalepsy in mice. Indian J Pharmacol. 2020;31(6):434

13. Naidu PS, Kulkarni SK. Excitatory mechanisms in neuroleptic-induced vacuous chewing movements (VCMs): Possible involvement of calcium and nitric oxide. Behav Pharmacol. 2001;12(3):209-16.

14. Crowley JJ, Adkins DE, Pratt AL, Quackenbush CR, DenOord EJV, Moy SS, et al. Antipsychotic-induced vacuous chewing movements and extrapyramidal side effects are highly heritable in mice. Pharmacogenomics J. 2012;12(2):14755.

15. Fernandes VS, Santos JR, Leão AHFF Medeiros AM, Melo TG, Izídio GS, et al. Repeated treatment with a low dose of reserpine as a progressive model of Parkinson's disease. Behav Brain Res. 2012;231(1):154-63.

16. Faroog S, Sehgal A. Antioxidant activity of different forms of green tea: Loose leaf, bagged and matcha. Curr Res Nutr Food Sci. 2018;6(1):35-40.

17. Pal A, Kumar M, Saharan V, Bhushan B. Anti-oxidant and free radical scavenging activity of Ashwagandha (Withania sominifera L.) leaves. J Glob Biosci. 
2015;4(1):1127-37.

18. Patil R, Gadakh R, Gound H, Kasture S. Antioxidant and Anticholinergic Activity of Rubia cordifolia. Pharmacologyonline. 2011;2:272-8.

19. Wadenberg MLG, Kapur S, Soliman A, Jones C, Vaccarino F. Dopamine D2 receptor occupancy predicts catalepsy and the suppression of conditioned avoidance response behaviour in rats. Psychopharmacology. 2000;150(4):4229.

20. Nishchal BS, Rai S, Prabhu MN, Ullal SD, Rajeswari S, Gopalakrishna HN. Effect of Tribulus terrestris on haloperidol-induced catalepsy in mice. Indian J Pharm Sci. 2014;76(6):564-7.

21. Camfield DA, Stough C, Farrimond J, Scholey AB. Acute effects of tea constituents L-theanine, caffeine and epigallocatechin gallate on cognitive function and mood: A systematic review and meta-analysis. Nutr Rev. 2014;72(8):507-22.

22. Nabavi SM, Daglia M, Braidy N, Nabavi SF. Natural products, micronutrients and nutraceuticals for the treatment of depression: A short review. Nutritional Neuroscience: Taylor and Francis Ltd. 2017;20(3):180-94. Available from: https:// www.tandfonline.com/ doi/ abs/ 10.1080/1028415X.2015.1103461.

23. Elsaid FG, Shati AA, Sarhan MA. Role of Matricaria recutita L. and Asparagus officinalis L. against the neurotoxicity of diazinon in rats. J Basic Appl Zool. 2015;72:26-35.

24. Pereira AG, Poli A, Matheus FC, DeBortoli DSL, Fadanni GP, Izídio GS, et al.
Temporal development of neurochemical and cognitive impairments following reserpine administration in rats. Behav Brain Res. 2020;383:112517.

25. Mirza B, Ikram H, Bilgrami S, Haleem DJ, Haleem MA. Neurochemical and behavioral effects of green tea (Camellia sinensis): A model study. Pak J Pharm Sci. 2013;26(3):511-6.

26. Lalert L, Kruevaisayawan $H$, Amatyakul P, Khongsombat O. Neuroprotective effects of $A$. racemosus root extract in ovariectomized rats. J Physiol Biomed Sci. 2013;26(1):18-22.

27. Hedgecock T, Phillips A, Ludrick B, Golden T, Wu N. Molecular Mechanisms and Applications of a Reserpine-Induced Rodent Model. SSR Inst Int J Life Sci. 2019;5(1):2160-7.

28. Lebowitz JJ, Khoshbouei H. Heterogeneity of dopamine release sites in health and degeneration. Neurobiol Dis. 2020;134(11):104633. Available from: https:// doi.org/10.1016/j.nbd.2019.104633.

29. Lampariello L, Cortelazzo A, Guerranti R, Sticozzi C, Valacchi G. The magic velvet bean of Mucuna pruriens. J Tradit Complement Med. 2012;2(4):331-9.

30. Cassani E, Cilia R, Laguna J, Barichella M, Contin M, Cereda E, et al. Mucuna pruriens for Parkinson's disease: Low-cost preparation method, laboratory measures and pharmacokinetics profile. J Neurol Sci. 2016;365:175-80.

31. Cousins MS, Carriero DL, Salamone JD. Tremulous jaw movements induced by the acetylcholinesterase inhibitor tacrine: Effects of antiparkinsonian drugs. Eur J Pharmacol. 1997;322(2-3):137-45.

Article History: Submission Date : 21-08-2020; Revised Date : 18-09-2020; Acceptance Date : 09-11-2020.

Cite this article: Giri MA, Bhalke RD, Prakash KV, Kasture SB. Antiparkinsonian and Antioxidant Effects of Hydroalcoholic Extract of Camellia sinensis, Asparagus racemosus, Mucuna pruriens and their Combination. Int. J. Pharm. Investigation, 2020;10(4):569-74. 